It will be evident that the operation raises more questions than it answers, but whatever the explanation it does seem to be effective in alleviating the attacks of asthma in some cases. It deserves wider investigation.

\section{Summary}

Eight cases of asthma of various types have been treated by bilateral excision of the carotid body, and one by unilateral denervation. Those associated with chronic bronchitis and emphysema have been improved rather than those of typically allergic asthma.

\section{Acknowledgment}

My thanks are due to Dr. S. C. Chen for her help with these cases and with the translation of the Chinese and Japanese articles.

\section{REFERENCES}

I. Kyushu Univ. Med. F., November, 1943 (Japanese)

2. Moukden Med. Col. F., October, 1947 (Chinese)

3. LEVY and SEABURY (1947), $\mathcal{F}$. of Allergy, 18, 244

4. LECOMPTE, P. M. (1948), Am. F. Path., 24, 305.

5. RAY, B. S., and STEWART, H. J. (1948), 'Glossopharyngeal

Nerve in Carotid Sinus Reflex,' Surgery, 23, 4I I.

6. TCHIBUKMACHER, N. B. (1938), 'Surg. Anat. of Carotid Sinus Nerve' Surg. Gyn. Obst., 67,740 .

7. SCHMIDT, C. F., and COMROE, J. H. (1940), ' Function of Carotid Body,' Phys. Rev., 20, 1 I 5.

8. TSCHIRGI, R. D., and GERARD, R. W. (1947), 'Gasp Reflex,'Am. F. Phys., r 50, 358 .

9. COMROE, J. H., and BOTELHO, S. (1947), Am. Y. Med.

ro. RIENHOFF, W. F., and GAY, L. N. (1938), Arch. Surg. Chicago, 37, 456, quoted in Brit. Enc. Med. Prac. S., 1939, p. 232.

I I. CHRISTIE, R. V. (1937), Brit. Enc. Med. Pract., 4, 395.

12. COKE, M., and DUNLOP, H. A. (1932), Lancet, 2, 1050.

13. WEISS, S., and ROBB, G. P. (I933), 'Cardiac Asthma, Ұ.A.M.A., 100, 1845 .

\title{
MARROW PUNCTURE AND ITS AID IN DIAGNOSIS
}

\author{
By Angus E. Brewer, M.R.C.S. \\ Clinical Pathologist, Hampstead General Hospital, Royal. Free Hospital Group
}

A patient's blood count reflects the condition and the function of the bone marrow. An abnormal blood picture that is inadequately explained by the clinical condition is a direct indication to examine the marrow.

The first attempt at marrow biopsy was made at the beginning of this century by trephining the femoral epiphysis or the upper third of the tibia. The inconstant presence of active marrow at these sites produced indifferent results and it was not until Seyfarth described trephining of the sternum in 1923 that widespread interest was founded. Trephining is somewhat laborious and the procedure was much simplified when Arinkin ${ }^{1}$ in 1927 showed that suitable material for examination might be obtained by puncturing the sternum with a wide gauge needle.

Since then many varieties of needle consisting of a trochar and cannula have been designed. The Salah needle is now in general use and has an adjustable stop which acts as a safeguard against over-penetration and enables the operator to gauge the depth of the needle point.

The site usually chosen for puncture is the manubrium or the body of the sternum between the second and the third rib in the mid-line. Recently successful puncture of the spines of the vertebrae, the iliac crests and the ribs has been described and the marrow thus obtained in normal subjects has been identical with that from the sternum ${ }^{234}$.
The patient is given a sedative and lies flat in the bed. The skin and periosteum are infiltrated with 2 per cent. novocain. The needle is pushed vertically through the skin and into the bone with a firm boring motion. The amount of pressure necessary will depend on the thickness and the condition of the bone. A give is usually felt as the marrow cavity is entered. The stylet is withdrawn and a $2 \mathrm{cc}$. sterile paraffined syringe attached and 0.2 cc. only of marrow aspirated, thus preventing excessive dilution with blood. The stylet is replaced, the needle withdrawn and the wound sealed with collodion. The patient should then be at rest in bed for some hours.

\section{The Dangers of Sternal Puncture}

Haemorrhage and haematoma may occur, particularly in blood dyscrasias, but are never serious unless the patient has been allowed up immediately. Very rarely death from shock has occurred and adequate sedation would seem to be a necessary precaution. Infection, a potential possibility, has not been noted. Puncture of the heart has only been reported where an unguarded or unsuitable needle has been used.

It has been stated that haemophilia is the only contraindication.

\section{Normal Marrow and the Limitations of the Biopsy}

Normal marrow is semifluid and consists of 
islands of proliferating cells, blood channels and fat (Fig. 7). Suction applied through the syringe causes a local disruption of this delicate tissue and the material obtained is a chance mixture of these elements. Even though standard procedures are adhered to and a constant volume of material is withdrawn normal marrow counts show a wide range of numerical values. $A$ report as to the general histological features, the character of the red, white and platlet maturation, and the presence of any abnormalities is essential if the report is to be of value to the clinician and not merely a mass of figures. To this should be added a note as to the relationship of the marrow findings to the blood count and to the general clinical picture.

Patchy lesions such as some cases of multiple myeloma may be completely missed, though the chances of this are much less if marrow puncture is repeated at other sites when the apparently normal results of first puncture are suspect.

In those pathological conditions, e.g. myelosclerosis, where the marrow loses its semi-fluid state, aspiration is a failure and material must be obtained by trephining.

\section{The Preparation of Marrow Specimens}

The 0.2 cc. of marrow obtained by suction is expelled on to a glass slide. From this a number of smears are spread on other slides in a similar manner to peripheral blood smears. The 'fluid' part of the specimen may then be absorbed with blotting paper, leaving the small fragments of marrow on the slide. Some of these are pressed out between two slides to give impressions and thin sections. Others are put into Zenker fixing fluid and paraffin sections made. All preparations are stained with Jenner-Giemsa or other blood stains and the paraffin sections in addition with haematoxylin and eosin.

\section{The Indications for Marrow Puncture and its Aid to Diagnosis}

These are illustrated by case histories grouped under five general headings as follows:

\section{(I) Anaemia which Fails to Respond to Treatment}

\section{CASE I}

A small, thin, pale woman, aged thirty-nine, was seen in O.P. complaining of weakness, dyspnoea and menorrhagia. The blood picture (Hb. 46 per cent.) suggested the severe hypochromic microcytic anaemia frequently seen in women of this age (see table, Case I $(a)$ ).

Comprehensive iron therapy failed to produce any improvement. In a few months her $\mathrm{Hb}$. had fallen to 32 per cent. and she had developed a leucopenia $(\mathrm{I}, 200$ per $\mathrm{cm}$.), although the red cells themselves now appeared more normal in size, shape and staining (see table, Case I $(b)$ ). $\frac{\widehat{D}}{3}$

Material obtained at sternal puncture showed $\stackrel{a}{c}$ a very severe hypoplasia, the smears containing $\stackrel{.}{\Rightarrow}$ little more than fat spaces surrounded by blood $\stackrel{2}{\rightarrow}$ (Fig. I). Only a very occasional nucleated red $\overline{0}$ cell and myelocyte could be found and the scantr 흠 cells present consisted of monocytes, lymphocytes $\frac{\bar{m}}{\overline{7}}$ and an undifferentiated cell of reticulo-endothelial $\overparen{\nabla}$ type. These changes were thought to be a phase of marrow exhaustion due to continued extreme anaemia and persistent menorrhagia.

Similar pictures were obtained when the puncture was repeated after transfusions, hysterectomy and intensive therapy with every possible haematinic. Puncture of the third lumbar vertebral spine yielded marrow showing identical histology.

A diagnosis of apastic anxemia was made, is although the presence of the undifferentiated cells in the marrow was not adequately explained. The patient was kept alive by repeated transfusion. Some $m$ onths later the spleen and several of the sunerficial lymph glands enlarged and histology showed a reticulosis, the abnorm 1 cells being the same as those first noticed in the bone marrow.

\section{CASE 2}

A stocky, well-b iilt man, aged fifty, complained of gradual loss of energy and increasing dyspnoes over many months. Apart from considerable pallor and a tachycardia, no clinical abnormalities were evident, but a routine blood count showed a very marked hypochromic normocytic anaemia (Hb. 34 per cent. - see table).

Immediate transfusion was followed by intensive iron therapy, but the blood failed to improve and the reticulocyte count remained below I per cent.

At sternal puncture very little material was $\underline{3}$. obtained. It consisted of blood containing a few fragments of fatty tissue. No marrow cells could be found and the only information obtained was that the marrow had lost the normal semi-fluid character, which permits aspiration.

Further material for examination was obtained by trephine. Following preliminary local anaesthesia, the skin and periosteum over the sternum at the level of the second rib was incised. A disc of bone with adherent marrow was removed with a $\mathrm{I} \mathrm{cm}$. trephine and additional marrow obtained by curettage. The periosteum was replaced but not sutured and the skin wound closed.

Sections showed the marrow to be almost entirely replaced by fibrous tissue in which were emeshed fat, isolated haematopoietic cells and very occasional islands of blood-forming tissue (Fig. 2). These changes are typical of myelo- 


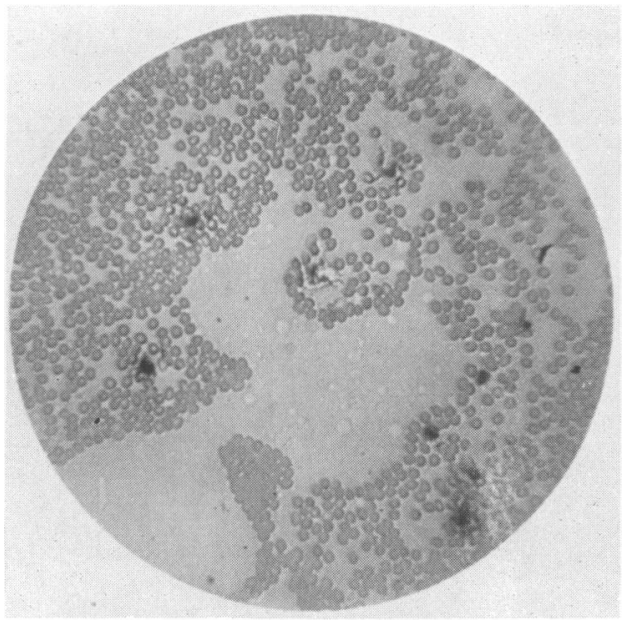

FIG. I.-Marrow from Case I. Fat spaces surrounded with blood.

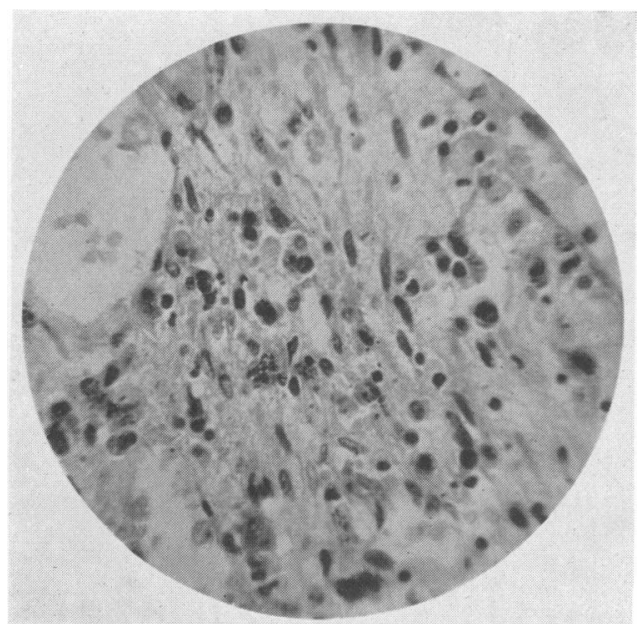

Fig. 2.-Myelosclerins. Marrow from Case 2.

FIG. 4.- Small group of carcinoma cells in the marrow
FIG. 3.--Marrow of normal cellularity containing atypical cells (marked X).

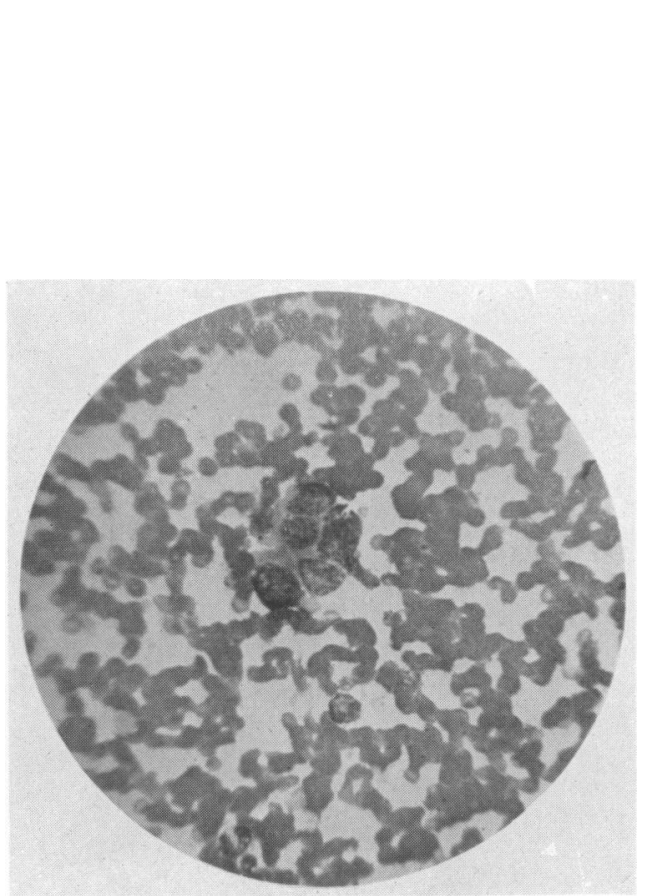
of Case 5 .






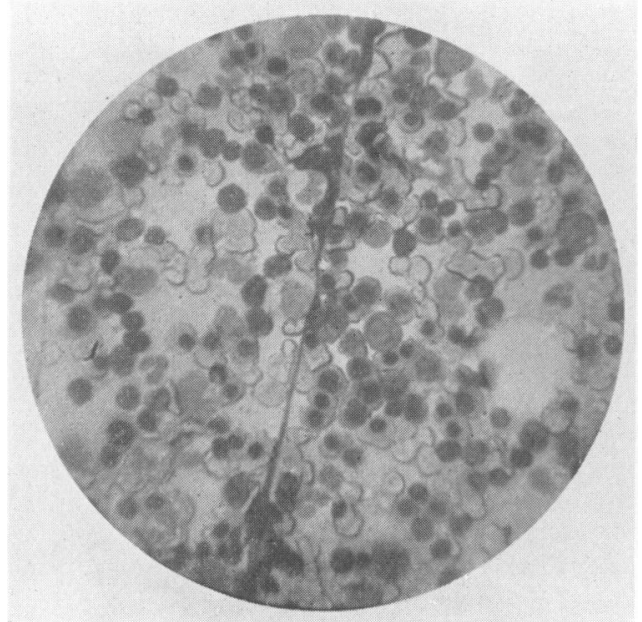

Fig. 5- - Hyperplastic marrow from Case 6.

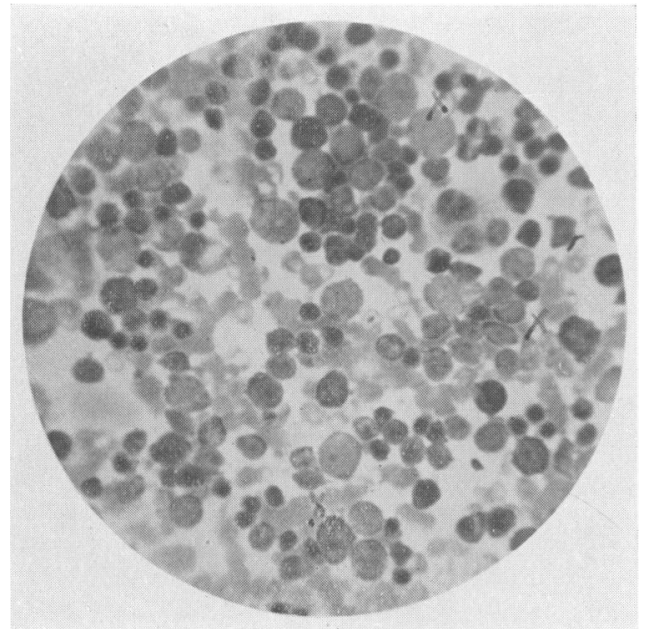

FIG. 6.-Leukaemic marrow from Case 7. Obliteration of fat spaces by proliferating myeloblasts marked $\mathrm{X}$.

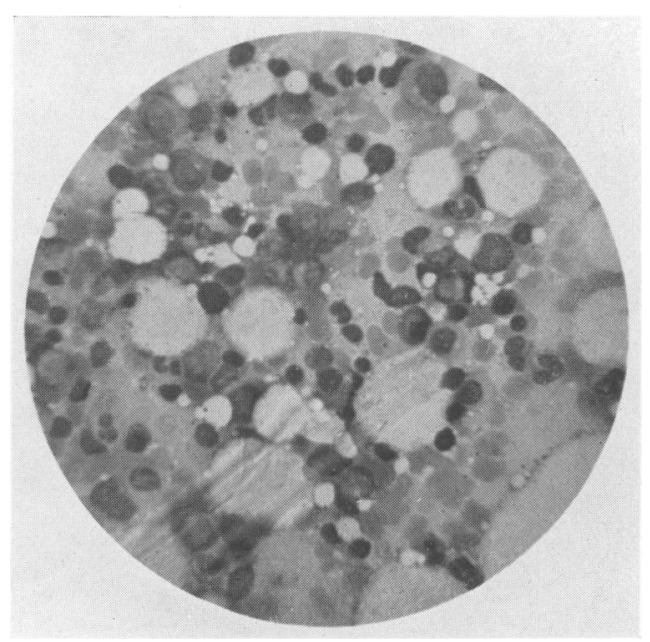

Fig. 7.-Normal red marrow. 
sclerosis, and in view of the clinical and haematological history, it seemed reasonable to accept this picture as a generalized condition of the marrow rather than a localized process in the sternum. In this case practically no blood-forming tissue remained and there was no chance of a return to any useful degree of haematopoiesis.

The patient was kept alive for 14 months by repeated transfusion, during which time he developed a considerable splenomegaly.

\section{(II) Unexplained Illness Accompanied by an Abnormal Blood Picture}

\section{CASE 3}

A tall, well-built, but thin, man of sixty-five consulted his doctor with a thrombosis of the left calf following unaccustomed exercise. He also reported increasing weakness and loss of colour over the last nine months. He developed a fever. without any definite clinical signs and complained of some indefinite pains in the right side of the chest. A blood count showed a severe normocytic normochromic anaemia ( $\mathrm{Hb} .44$ per cent.) and a marked leucopenia ( 1,000 per $\mathrm{cm}$.), the neutrophils having a pronounced degenerative and toxic shift. Other laboratory investigations were negative and clinical and X-ray examinations failed to determine a diagnosis. A sternal puncture then undertaken revealed a hypoplastic marrow containing 24 per cent. of plasma myeloma cells and the diagnosis of multiple myeloma was established.

\section{CASE 4}

A few days after extraction of a carious tooth a married woman of twenty-eight developed a swinging temperature with a considerable degree of general malaise, mild gingivitis and conjunctivitis and a transient morbilliform rash. Blood cultures were negative. A blood count showed a mild normochromic anaemia and a leucopenia with a relative eosinophilia. There were marked degenerative and toxic changes in the neutrophils.

During the next ten days the general condition became much worse. The gingivitis became ulcerative and haemorrhagic. The spleen and cervical glands enlarged. There were segveral attacks of urticaria. The $\mathrm{Hb}$. fell to 55 per cent. The leucocytes rose to 8,000 , with monocytes 22 per cent. and eosinophils 14 per cent. Some of the monocytes showed atypical and primitive characteristics and resembled the cells seen in glandular fever. However, a Paul Bunnell test was negative and the patient's condition was so grave that a clinical diagnosis of leukaemia was suggested.

At sternal puncture a marrow of normal cellularity was obtained which contained ro per cent. of atypical cells similar to those seen in the blood picture. Red cell tissue appeared somewhat reduced although maturation was normal. Ne utrophil maturation showed toxic changes and a shift towards immaturity (Fig. 3).

These findings were not those of a leukaemia, but supported the diagnosis of a virus infection of the glandular fever type, causing toxic depression of bone marrow function and a reactive hyperplasia of the reticulo-endothelial system resulting in abnormal mononuculer cells.

\section{(III) Macrocytic Anaemia}

In many cases of macrocytic anaemia the clinical signs and a detailed blood count enable the diagnosis to be made, e.g. pernicious anaemia, some cases of carcinomatosis, of hepatic cirrhosis and hypothyroidism. In obscure cases help must be obtained from marrow examination.

\section{CASE 5}

An active man of sixty-five had for some years suffered with chronic bronchitis. Recently his cough had become worse and he complained of increasing fatigue and loss of weight. A blood count showed a macrocytic anaemia (Hb. 55 per cent.) with a reticulocytosis of 7 per cent. and an occasional normoblast. The leucocytes were I0,000 with a considerable inflammatory shift (myelocytes 5 per cent.). The findings were those of a leuco-erythroblastic anaemia.

Carcinoma of the lung with bony secondaries was suspected, but the $\mathrm{X}$-ray examinations were inconclusive and, as the cause of the macrocytic anaemia remained uncertain, sternal puncture was carried out.

The marrow obtained was very hyperplastic, there being numerous early cells of both red and white series. Proerythroblasts and early normoblasts were particularly noticeable and 30 per cent. of red cell maturation was macronormoblastic with early haemoglobinization. There were no megaloblasts, the remainder of the red cell tissue being normoblastic.

Thus a picture was obtained which was typical in its unproductive and abnormal hyperplasia of secondary carcinoma involving the marrow. In an exhaustive search of the films several small groups of carcinoma cells were found (Fig. 4).

With this definite evidence the diagnosis of carcinoma of the lung was then made with confidence and was confirmed by subsequent postmortem examination.

\section{Case 6}

A previously healthy, married woman of thirtyfive complained of indefinite malaise, increasing shortness of breath and vague abdominal pains. Apart from a slight fever and a tachycardia, clinical 


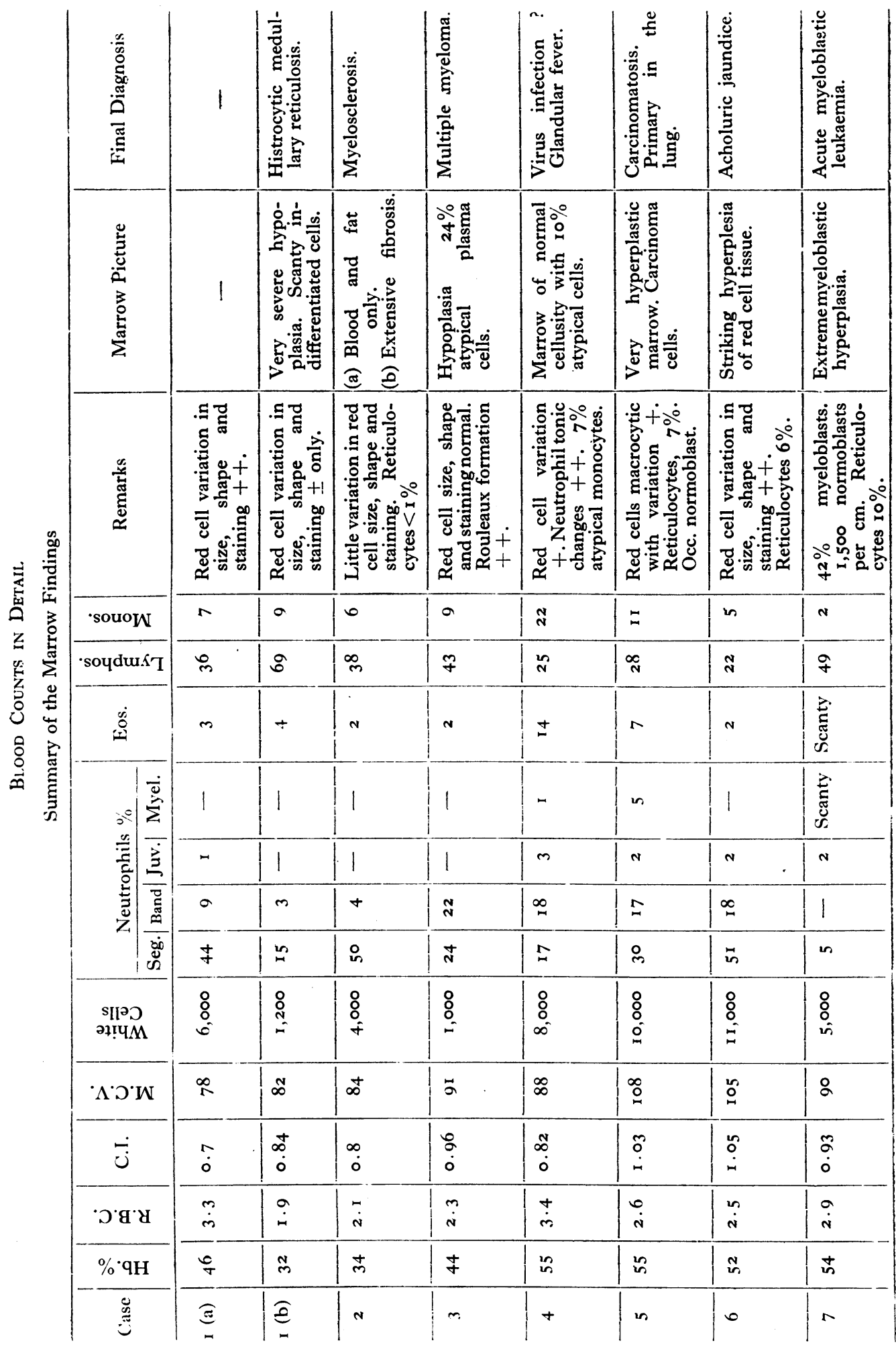


examination failed to reveal any abnormalities. A blood count showed a macrocytic anaemia ( $\mathrm{Hb}$. 52 per cent.) with considerable variation in the size, shape and staining of the cells and a reticulocytosis of 6 per cent. A suggestion that the patient was slightly jaundiced was confirmed by a serum bilirubin estimation giving a total of 1.5 mg. with an indirect Vandenbergh reaction. The urine did not contain bile.

The fragility of the red cells in hypotonic salines was normal and no haemolytic antibodies were detected in the patient's serum.

Since neither the cause of the symptoms nor the nature of the macrocytic anaemia were apparent, sternal puncture was advised. The marrow obtained showed a striking hyperplasia of the red cell tissue with a relative decrease in maturing granulocytes. The fat spaces were obliterated by masses of proerythroblasts, early and intermediated normoblasts. Maturation was normoblastic with a small proportion of macronormoblasts showing early haemoglobinization (Fig. 5).

The complete absence of megaloblasts ruled out pernicious anaemia and the findings were compatible with a marrow doing its best to compensate for excessive blood destruction.

With this evidence a diagnosis of acholuric jaundice was made, the case being one of the few not showing an increased red cell fragility in hypotonic salines.

\section{(IV) Final Confirmation of a Diagnosis}

As mentioned above it is frequently possible to make a diagnosis from the clinical condition and the blood count. Examination of the marrow in such cases only adds further confirmatory evidence, but nevertheless is a valuable and justifiable procedure where the diagnosis is serious and the prognosis alarming to the patient and his relatives.

\section{CASE 7}

A prosperous and hard-working business man who had previously been in very good health complained suddenly to his doctor of tiredness and inability to concentrate. Routine clinical examination was normal. The usual holiday rest and tonics produced no improvement. A blood count then showed a normocytic, normochromic anaemia (Hb. 54 per cent.) with $\mathrm{I}, 500$ nucleated red cells per $\mathrm{cm}$. and a reticulocytosis of 10 per cent. The leucocyte total was 5,000 , but only 7 per cent. of these were neutrophils, 42 per cent. were primitive cells resembling myeloblasts.

With such definite evidence there seemed no doubt that the condition was one of acute myeloblastic leukaemia.
This startling and serious diagnosis was confirmed by sternal puncture which showed a marrow crowded with myeloblasts with almost complete obliteration of the fat slaces. Red cell tissue and maturing granulocytes were greatly reduced (Fig. 6).

The patient died in six weeks.

\section{(V) Miscellaneous Conditions}

Culture of the marrow in cases of bacterial endocarditis and septicaemia has yielded positive results where blood culture has failed ${ }^{5} 6$.

Drip transfusions may be given into the marrow of the sternum through a Salah needle when the peripheral veins have been damaged. In children under four the tibia may be used. The procedure followed is similar to diagnostic puncture, though it is better to have a winged guard attached to the needle, which can be strapped down to the chest wall.

In malaria the parasite has been found in the marrow when repeated blood examinations have been negative. Similarly in kala-azar, marrow puncture has been successful in demonstrating the parasite Leishmania Donovani within the endothelial cells.

In lipoidosis such as Gaucher's disease the typical large lipoid-containing cells may often be found in the marrow associated with hyperplasia of the erythroid and myeloid tissues.

\section{Summary}

A brief introduction is given to the development and technique of marrow puncture. The procedure is simple and, with adequate care, almost devoid of risk, though experience is necessary to ensure trustworthy results.

Marrow puncture enables a direct and detailed examination to be made of a disordered tissue and the specimen obtained exhibits within certain limitations the state and function of the marrow at that moment.

A number of cases are described to illustrate the indications for marrow puncture and the aid a detailed examination and a report correlated with the clinical condition and the blood count may give to diagnosis.

My thanks are due to Mr. John S. Sheppard of the Royal Free Hospital for the photographs.

\section{REFERENCES}

I. ARINKEN, M. J. (1929), Folia Haematol., 38, 233.

2. NORDENSEN, N. G. (1935), 'Studies on Bone Marrow,' Stockholm, Bortzells Esselte.

3. RUBSTEIN, M. A. (1947), 'Iliac Crest Versus Sternal Marrow Puncture,' Exhibition Ámer. Med. Assn. Convention.

4. LOGE, P. J. (1948), Blood, 3, 198 .

5. FALCONER, E. H., and LEONARD, M. E. (1941), Ann. Int : Med., I5, 446.

6. MACDONALD, A. (r94r), Lancet, I, 147.

7. WINTROBE, M. M. (1946), 'Clinical Haematology.' 